\title{
Pricing Range Accrual Interest Rate Swap Employing LIBOR Market Models with Jump Risks
}

\author{
Shih-Kuei Lin \\ Department of Money and Banking, National Chengchi, Taiwan, ROC \\ Shin-Yun Wang* \\ Department of Finance, National Dong Hwa University, Taiwan, ROC \\ Carl R. Chen \\ Department of Economics and Finance, University of Dayton, Ohio, USA
}

\begin{abstract}
As an important economic index, interest rates are assumed to be constant in the Black and Scholes model (1973); however, they actually fluctuate due to economic factors. Using a constant interest rate to evaluate derivatives in a stochastic model will produce biased results. This research derives the LIBOR market model with jump risks, assuming that interest rates follow a continuous time path and tend to jump in response to sudden economic shocks. We then use the LIBOR model with jump risk to price a Range Accrual Interest Rate Swap (RAIRS). Given that the multiple jump processes are independent, we employ numerical analysis to further demonstrate the influence of jump size, jump volatility, and jump frequency on the pricing of RAIRS. Our results show a negative relation between jump size, jump frequency, and the swap rate of RAIRS, but a positive relation between jump volatility and the swap rate of RAIRS. When new information emerges, the resulting increase in jump size reduces the value of LIBOR, which in turn lowers the value of RAIRS. Similarly, the value of RAIRS declines when the jump frequency of LIBOR increases. This is because jump frequency is associated with higher uncertainty risk, and the market pays out a premium for bearing such risk. On the other hand, when jump volatility increases, both parties must agree to a higher swap rate because the floating rate payer is subsidized by the fixed rate payer for bearing risk.
\end{abstract}

Keywords: Stochastic model in continuous time interest rate, LIBOR market model, jump risks, Range Accrual Interest Rate Swap (RAIRS).

* Corresponding author: Shin-Yun Wang, Department of Finance, National Dong Hwa University, 1, Sec. 2, Da-Hsueh Rd., Shou-Feng, 974 Hualien, Taiwan. Tel: (03)863-3136; Fax: 
(03)863-3130; e-mail: gracew @ mail.ndhu.edu.tw. 


\section{Pricing Range Accrual Interest Rate Swap Employing LIBOR Market Models with Jump Risks}

\section{Introduction}

Interest rates constitute an important economic index, and unexpected movement in interest rates may cause changes in the pricing of financial assets. Therefore, interest rate swaps are often used by investors to alter their exposure to interest rate risk. Since interest rate swaps are a major instrument in global financial markets, the ability to price interest rate derivatives accurately is of great importance.

First introduced by Vasicek (1977), the short rate model following a mean reverting process may produce negative interest rates. To overcome this disadvantage, Cox, Ingersoll and Ross (1985) (CIR) introduce a model in which expectations, risk aversion, investment alternatives, and preferences about the timing of consumption all play a role in determining bond prices. By further assuming that all interest rate claims are priced contingent on only the short rate, CIR derive an equilibrium pricing model that relies on a continuous arbitrage argument.

Ho and Lee (1986) are the first to incorporate a discount function into the pricing of contingent claims. Given a term structure, their model derives the subsequent stochastic movement of the term structure such that the movement is arbitrage-free. However, the short rate movement is assumed to be constant, which results in a failure to derive an interest rate that is always consistent with the market interest rate. Therefore, Hull and White (1990) incorporate the discount function into the Vasicek model and relax the constant short rate assumptions of Ho and Lee (1986) to derive the one-factor equilibrium term structure model, which is capable of determining a short rate process that is consistent with the current term structure of interest rates. Furthermore, Ho and Lee (1986), and Hull and White (1990) apply 
term structure equilibrium models to the pricing of discount bonds. In these models, all discount bonds are priced relative to the stochastic short rate such that there are no arbitrage opportunities in their trading. Researchers have since developed such long-term interest rate models as the instantaneous forward rate model (Heath, Jarrow and Morton, 1992) and the LIBOR market model (Brace, Gatarak and Musiela, 1997), all based on the no-arbitrage condition.

Merton (1976) points out that since stock price dynamics do not follow a continuous sample path, they should be modeled as a "jump" process with a non-continuous sample path that reflects the impact of the emergence of important new information. Later, research increasingly focused on the interest rate jump-diffusion model. Shikarawa (1991) employs a pure jump model to price derivatives; Björk, Kabanov and Runggaldier (1997) extend the Heath, Jarrow and Morton (1992) "drift condition" to incorporate market point process to derive the instantaneous forward rate jump-diffusion model. The jump size in the market point process is assumed to be drawn from a continuous distribution with multiple jump processes, each of which is associated with a constant jump value scaled by time-deterministic jump volatility. Such a model allows for solving for a no-arbitrage condition and a risk-neutral probability measurement. Finally, following the model of Björk, Kabanov and Runggaldier (1997), Chiarella and To (2003) propose an instantaneous forward rate jump-diffusion model. Assuming that multiple market point processes are independent and follow a Poisson process, Chiarella and To (2003) derive no-arbitrage pricing of interest rate futures in a risk-neutral condition. Furthermore, they use the full-information-likelihood function to prove the pricing accuracy of interest rate futures after incorporating the jump process.

The use of interest rate with jump risk is more consistent with real world observations (e.g., the emergence of important economic information often results in discontinuous interest rate movement). For example, China recently increased interest rates to cool down an 
overheated economy that resulted from the maintenance of low interest rates to lure foreign investment. Figure 1 shows that movements in LIBOR from 1998 to 2005 did not follow a smooth path and were discontinuous. Prior to December 23, 1998, fluctuations in interest rates tended to be small, ranging between $4.9 \%$ and $5.0 \%$. However, interest rates suddenly jumped to $7.25 \% \sim 7.27 \%$ in late-December 1998 , returning to their previous level shortly thereafter. Hence, movements in interest rates are often not smooth but rather, discontinuous-they tend to jump following unexpected world events.

Therefore, using a constant interest rate over a continuous time period to evaluate derivatives in a stochastic model will produce biased results. The present research has two objectives. We first derive the LIBOR market model with jump risk assuming that interest rates tend to jump in response to sudden economic shocks. We then use this LIBOR model with jump risk to price a Range Accrual Interest Rate Swap (RAIRS). Given that the multiple jump processes are independent of each other, we then employ numerical analysis to demonstrate the impact of jump size, jump volatility and jump frequency on the pricing of the RAIRS. Our results show a negative relation between jump size, jump frequency, and the swap rate of RAIRS, but a positive relation between jump volatility and the swap rate of RAIRS.

This paper proceeds as follows. RAIRS and the model assumptions are introduced in Section 2. Section 3 incorporates the interest rate jump process to derive the LIBOR market model with jump risk. The RAIRS pricing model is then derived to incorporate the influence of jump size, jump volatility, and jump frequency. Numerical analysis demonstrating the relationship between swap rate and jump size, jump frequency, and jump volatility are presented in Section 4. Section 5 details our conclusion. 


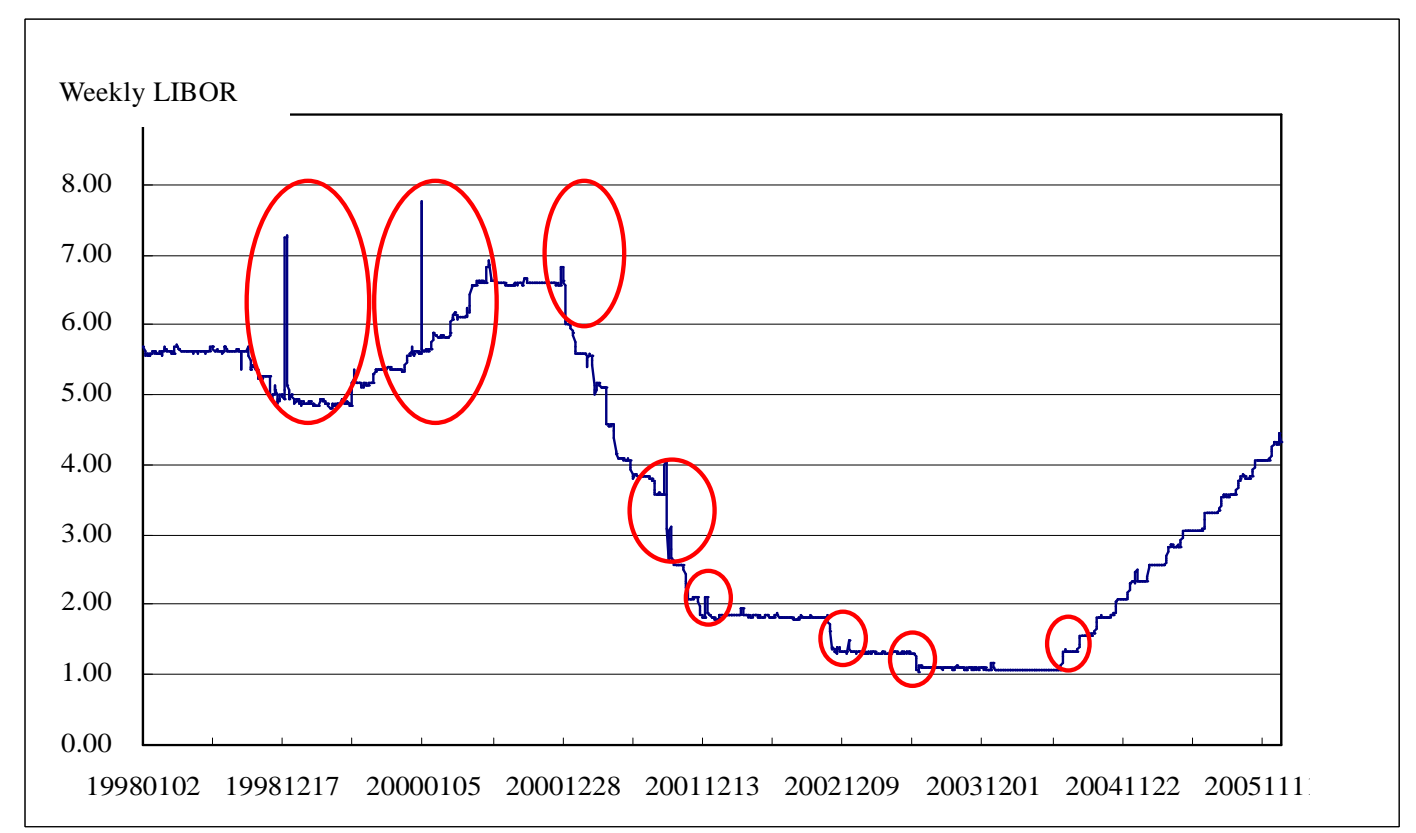

Figure1. Weekly LIBOR: US Dollars

Data source: Economagic.com: Economic Time Series, http://www.economagic.com.

\section{The Range Accrual Interest Rate Swap (RAIRS) Contract}

Consider a hypothetical 1-year RAIRS initiated on $T_{0}$, with a termination date $T_{4}$, between counterparties $\mathrm{A}$ and $\mathrm{B}$. We assume A agrees to pay $\mathrm{B}$ at a fixed interest rate per annum on a notional principal amount of $\$ F$, and in return $\mathrm{B}$ agrees to pay $\mathrm{A}$ the 3-Month USD LIBOR rate on the same notional principal amount. Hence A is the fixed-rate payer and $\mathrm{B}$ is the floating-rate payer. We further assume that this agreement specifies that payments are to be swapped every 3 months and that the interest rate, $K$, is compounded annually. There are four swaps each year. A schematic of this swap agreement is shown in Figure 2. If the LIBOR falls within $K_{1}$ and $K_{2}$, A would pay B an amount equal to $\$ F \times K / 4$. This is the interest on the $\$ F$ principal for 3 months at interest rate $K$. On the other hand, B would pay A interest on the $\$ F$ principal at the 3-month LIBOR rate. That is, $\mathrm{B}$ would pay $\mathrm{A}$ an amount equal to $\$$ $F \times a \times N / D . K_{1}$ represents interest rate floor; $K_{2}$ is the interest rate cap; $K$ denotes the 
fixed rate; $F$ is the notional principal; $N$ shows the total number of calendar days in the period between swaps; and $D$ is the total number of calendar days in the year. (See Table 1 and Figure 2)

Table 1. The content of a Range Accrual Interest Rate Swap

\begin{tabular}{|l|l|}
\hline Notional principal & $F$ \\
\hline Currency & USD $(\$)$ \\
\hline Trade type & Range Accrual Interest Rate Swap \\
\hline Trade date & $T$ \\
\hline Effective date & $T_{0}$ \\
\hline Termination date & $T_{4}$ \\
\hline Duration & 1 year \\
\hline Fixed rate payer & A \\
\hline Fixed rate & $K$ \\
\hline Fixed rate payment dates & $\begin{array}{l}\text { Payments are to be swapped every } 3 \text { months; } \\
\text { there are four exchanges of payment. }\end{array}$ \\
\hline Fixed rate count convention & Actual/360 \\
\hline Reset date & The first day of each trading date \\
\hline Floating rate payer & B \\
\hline & $a \times \frac{N}{D}, N$ is the total number of calendar days in \\
Floating rate payment & $\begin{array}{l}\text { the period between swaps, } D \text { is the total number } \\
\text { of calendar days in a year. }\end{array}$ \\
\hline Range accrual interest rate interval & {$\left[K_{1}, K_{2}\right]$} \\
\hline Floating rate & 3 -Month USD LIBOR \\
\hline
\end{tabular}

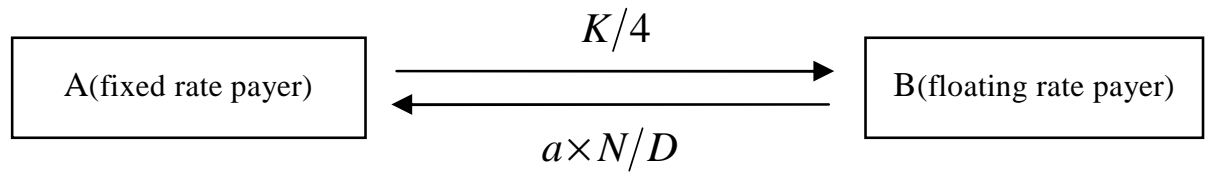

Figure 2. The contract form of RAIRS 


\section{LIBOR Market Model with Jump Risk and the Pricing of RAIRS}

Merton (1976) argues that investors react swiftly to the arrival of important information, hence the sample path of stock prices does not satisfy the continuity property. To be sure, stock price dynamics can be decomposed into two components: (1) The "normal" variations in stock prices due to factors such as interest rate changes, temporary imbalances between supply and demand, and mild changes in the economic outlook. These factors often cause small changes in stock prices, which can be modeled by a standard geometric Brownian motion characterized by a constant variance per unit of time and a continuous sample path. This type of stock price change is called the "diffusion" process. (2) "Abnormal" variations in stock prices that result from the sudden emergence of important information, often resulting in dramatic stock price changes. Typically, such information is specific to the firm or industry; this type of price change is called a "jump" process.

The jump process is also applicable to interest rate changes. In the next section, we construct an instantaneous forward rate jump-diffusion model based on the framework of Björk, Kabanov, and Runggaldier (1997). Assuming that multiple market point processes are independent and follow the Poisson process, we incorporate the jump dynamics in the LIBOR stochastic process such that the instantaneous forward rate process of $d f(t, T)$ can be described as

$$
d f(t, T)=\underbrace{\alpha(t, T) d t+\sigma(t, T) d W(t)}_{\text {1st }}+\underbrace{\sum_{i=1}^{r} h_{i}\left(t, x_{i}, T\right) d N_{i}(t)}_{\text {2nd }},
$$

where $\alpha$ represents the changes in the instantaneous forward rate; $\sigma$ is the standard deviation of instantaneous forward rate; $d W(t)$ stands for the Wiener process of forward rate in $t ; d N_{i}(t)$ is the $i^{\text {th }}$ Poisson process with expected value $\lambda_{i} d t$, where $i=1,2, \ldots, r$; $h_{i}\left(t, x_{i}, T\right)$ is the $i^{\text {th }}$ function of the forward rate variations, where $i=1,2, \ldots, r$; and random 
variable $x$ stands for the jump size of forward rate. The first component of Eq. (1) is the "normal" variation in interest rate caused by factors such as a temporary imbalance between the supply of and demand for deposits/loans, causing small changes in the instantaneous forward rate. This component can be modeled by a standard geometric Brownian motion. The second component of Eq. (1) is the "abnormal" variation in interest rate due to the emergence of important new information about interest rates, resulting in dramatic impact on the instantaneous forward rate. The second component is the jump term of the interest rate stochastic, which follows $r$ independent Poisson processes.

Based upon Eq. (1), in the following subsections we: (1) derive the no-arbitrage condition of the LIBOR market model with $r$ independent jump risks, assuming that the model follows Brownian motion and $r$ jump processes; (2) convert the LIBOR market model from a risk-neutral measure to a forward measure; and (3) derive the pricing formula of RAIRS based upon the forward measure in the LIBOR market model.

\subsection{No-arbitrage condition and the stochastic process of LIBOR in risk-neutral probability}

In this subsection, the no-arbitrage condition of bonds is derived from the instantaneous forward rate process. Based on this no-arbitrage condition and the relationship between the instantaneous forward rate and LIBOR, we then derive the LIBOR market process under the risk-neutral measure.

The relationship between the value of a zero coupon bond and the forward rate is given by

$$
B(t, T)=\exp \left\{-\int_{t}^{T} f(t, u) d u\right\}
$$


where $B(t, T)$ is the price of a default-free pure discount bond; therefore, it can be considered equivalent to the value of $\$ 1$ to be received at time $T$. Let

$$
B(t, T)=\exp \left[-\int_{t}^{T} f(t, u) d u\right]=\exp [V(t, T)]
$$

then

$$
\begin{aligned}
d V & =d-\int_{t}^{T} f(t, u) d u=-\left[-f(t, t) d t+\int_{t}^{T} d f(t, u) d u\right] \\
& =f(t, t) d t-\int_{t}^{T}(\alpha(t, u) d t) d u-\int_{t}^{T}(\sigma(t, u) \cdot d W) d u-\sum_{i=1}^{r} \int_{t}^{T} h_{i}\left(t, x_{i}, u\right) d u \cdot d N_{i}(t) \\
& =f(t, t) d t-\alpha^{*}(t, T) d t-\sigma^{*}(t, T) d W-\sum_{i=1}^{r} \int_{t}^{T} h_{i}\left(t, x_{i}, u\right) d u \cdot d N_{i}(t)
\end{aligned}
$$

where $\alpha^{*}(t, T)=\int_{t}^{T} \alpha(t, u) d u, \sigma^{*}(t, T)=\int_{t}^{T} \sigma(t, u) d u$. Based upon Björk, Kabanov and Runggaldier (1997), modified with $i$ independent jump processes, we employ the Itô formula to derive the stochastic process value of the zero coupon bond as follows

$$
\begin{aligned}
d B(t, T) & =B(t, T) d x+\frac{1}{2} B(t, T)(d x)^{2} \\
& +\sum_{i=1}^{r}\left[\exp \left(-\int_{t}^{T} f(t, u) d u-\int_{t}^{T} h_{i}\left(t, x_{i}, u\right) d u\right)-\exp \left(-\int_{t}^{T} f(t, u) d u\right)\right] d N_{i}(t) .
\end{aligned}
$$

Substituting Eq. (1) into Eq. (3), we obtain

$$
\begin{aligned}
d B(t, T) & =B(t, T)\left\{R(t)-\alpha^{*}(t, T)+\frac{1}{2}\left[\sigma^{*}(t, T)\right]^{2}\right\} d t-B(t, T) \sigma^{*}(t, T) d W(t) \\
& +\sum_{i=1}^{r} \exp \left[-\int_{t}^{T} f(t, u) d u\right]\left\{\exp \left[-\int_{t}^{T} h_{i}\left(t, x_{i}, u\right) d u\right]-1\right\} d N_{i}(t) .
\end{aligned}
$$

where $R(t)$ is the spot rate. Discounting the zero coupon bond to derive a no-arbitrage condition in risk-neutral probability, and substituting the no-arbitrage condition into Eq. (1), 
we obtain the forward stochastic process in the no-arbitrage condition. First, we define the discount factor $D(t)$ as

$$
D(t)=\exp \left(-\int_{0}^{t} R(u) d u\right)
$$

Furthermore, $D(t) B(t, T)$ follows the Martingale process. That is, if we discount the zero coupon bond to time $t$ in the risk-neutral probability, the discounted price will be identical to the current price at time $t$, implying the absence of arbitrage, hence the intercept must be equal to zero. Therefore,

$$
\begin{aligned}
d[D(t) B(t, T)] & =-D(t) B(t, T) \sigma^{*}(t, T) d W^{Q}(t) \\
& +D(t) B(t-, T) \sum_{i=1}^{r}\left\{\exp \left[-\int_{t}^{T} h_{i}\left(t, x_{i}, u\right) d u\right]-1\right\}\left(d N_{i}(t)-\lambda_{i}^{Q} d t\right)
\end{aligned}
$$

Incorporating the discount factor from Eq. (4),

$$
\begin{aligned}
d(D(t) B(t, T))= & D(t) B(t, T)\left\{\left(-\alpha^{*}(t, T)+\frac{1}{2}\left[\sigma^{*}(t, T)\right]^{2}\right) d t-\sigma^{*}(t, T) d W(t)\right\} \\
& +D(t) B(t-, T) \sum_{i=1}^{r}\left\{\exp \left[-\int_{t}^{T} h_{i}\left(t, x_{i}, u\right) d u\right]-1\right\} d N_{i}(t) .
\end{aligned}
$$

Since under the no arbitrage condition the intercept is equal to zero, comparing Eq. (5) and (6),

we obtain

$$
-\alpha^{*}(t, T)+\frac{1}{2}\left[\sigma^{*}(t, T)\right]^{2}+\sum_{i=1}^{r}\left\{\exp \left[-\int_{t}^{T} h_{i}\left(t, x_{i}, u\right) d u\right]-1\right\} \lambda_{i}^{Q} f\left(x_{i}\right) d x_{i}=-\sigma^{*}(t, T) \theta(t), \text { for all } t
$$

where $\theta(t)$ is the risk premium of the diffusion rate. Since each zero coupon bond in a term structure must correspond to the no-arbitrage condition in the risk-neutral probability, 
differentiating Eq. (7) with respect to $T$, the no-arbitrage condition is obtained as

$-\alpha(t, T)+\sigma(t, T) \sigma^{*}(t, T)-\int_{0}^{\infty} h_{i}\left(t, x_{i}, T\right) \exp \left[-\int_{t}^{T} h_{i}\left(t, x_{i}, u\right) d u\right] \lambda^{Q} f\left(x_{i}\right) d x_{i}=-\sigma(t, T) \theta(t)$, for all $t,(8)$

where $f\left(x_{i}\right)$ is the probability distribution of stochastic variable $x_{i}$. By substituting the no arbitrage condition into Eq. (1), the instantaneous forward rate with $r$ independent jump-diffusion processes in risk-neutral probability becomes

$$
d f(t, T)=\alpha(t, T) d t+\sigma(t, T) \cdot d W^{Q}(t)+\sum_{i=1}^{r} h_{i}\left(t, x_{i}, T\right) d N_{i}(t)
$$

where $\alpha(t, T)=\sigma(t, T) \sigma^{*}(t, T)-\int_{0}^{\infty} \sum_{i=1}^{r} h_{i}\left(t, x_{i}, T\right) \exp \left[-\int_{t}^{T} h_{i}\left(t, x_{i}, u\right) d u\right] \lambda_{i}^{Q} f\left(x_{i}\right) d x_{i}$.

Similar to Brace, Gatarak and Musiela (1997), the stochastic process of LIBOR in risk-neutral probability can be derived using the relationship between instantaneous forward rate and LIBOR. Therefore, the relationship between forward rate and LIBOR is given by

$$
1+\delta L_{n}\left(t, T_{n}\right)=\exp \int_{T_{n}}^{T_{n}+\delta} f(t, u) d u
$$

where $d L_{n}\left(t, T_{n}\right)$ stands for the compounded forward LIBOR (from $T_{n}$ to $T_{n+\delta}$ ) at time $t$, and $\delta$ is the constant interval measured in year. Letting $Z\left(T_{n}, T_{n+\delta}\right)=\int_{T_{n}}^{T_{n+\delta}} f(t, u) d u$,

$$
\begin{aligned}
d Z & =\int_{T_{n}}^{T_{n}+\delta} d f(t, u) d u \\
& \left.=\int_{T_{n}}^{T_{n+\delta}} \sigma(t, u) d u\right\} d W^{Q}(t)+\int_{0}^{\infty} \sum_{i=1}^{r}\left[\int_{T_{n}}^{T_{n+\delta}} h_{i}\left(t, x_{i}, u\right) d u\right] d N_{i}(t) f(x) d x \\
& +\int_{T_{n}}^{T_{n+\delta}}\left\langle\frac{\partial}{\partial u}\left\{\frac{1}{2}\left[\sigma^{*}(t, u)\right]^{2}\right\} d u\right\rangle d t+\int_{0}^{\infty} \sum_{i=1}^{r} \frac{\partial}{\partial u}\left\{\exp \left[-\int_{T_{n}}^{T_{n+\delta}} h_{i}\left(t, x_{i}, u\right) d u\right]\right\} \lambda_{i}^{Q} d t f(x) d x .
\end{aligned}
$$


It follows that

$$
\begin{aligned}
d Z & =\int_{T_{n}}^{T_{n}+\delta} d f(t, u) d u+\sum_{i=1}^{r} \int_{0}^{\infty}\left\{\exp \left[-\int_{t}^{T_{n+\delta}} h_{i}\left(t, x_{i}, u\right) d u\right]-\exp \left[-\int_{t}^{T_{n}} h_{i}\left(t, x_{i}, u\right) d u\right]\right\} \lambda_{i}^{Q} d t f(x) d x \\
& +\int_{0}^{\infty} \sum_{i=1}^{r}\left[\int_{T_{n}}^{T_{n+\delta}} h_{i}\left(t, x_{i}, u\right) d u\right] d N_{i}(t) f(x) d x .
\end{aligned}
$$

According to the Itô formula and the jump stochastic process of Elliott (1982), the LIBOR jump-diffusion process follows

$$
\begin{aligned}
d L_{n}(t, T) & =\frac{1}{\delta} \exp \left[Z\left(T_{n}, T_{n+\delta}\right)\right] d\left[Z\left(T_{n}, T_{n+\delta}\right)\right]+\frac{1}{2 \delta} \exp \left[Z\left(T_{n}, T_{n+\delta}\right)\right] d\left[Z\left(T_{n}, T_{n+\delta}\right)\right] d\left[Z\left(T_{n}, T_{n+\delta}\right)\right] \\
& +\sum_{i=1}^{r} \frac{1}{\delta} \int_{0}^{\infty}\left\{\exp \left[Z\left(T^{-}\right)\right] \cdot \exp \left\{\int_{T_{n}}^{T_{n+\delta}} h_{i}\left(t, x_{i}, u\right) d u\right\}-\exp \left[Z\left(T^{-}\right)\right]\right\} d N_{i}(t) f(x) d x .
\end{aligned}
$$

Substituting $d Z\left(T_{n}, T_{n+\delta}\right)$ into Eq. (11) yields the jump-diffusion stochastic process of LIBOR as

$$
\begin{aligned}
d L_{n}\left(t, T_{n}\right)= & \frac{1}{\delta}\left[1+\delta L_{n}\left(t, T_{n}\right)\right]\left\{\left[\sigma^{*}\left(t, T_{n+\delta}\right)\right]^{2}-\sigma^{*}\left(t, T_{n+\delta}\right) \sigma^{*}\left(t, T_{n}\right)\right\} d t \\
& +\frac{1}{\delta}\left[1+\delta L_{n}\left(t, T_{n}\right)\right]\left\{\sigma^{*}\left(t, T_{n+\delta}\right)-\sigma^{*}\left(t, T_{n}\right)\right\} d W^{Q}(t) \\
& +\sum_{i=1}^{r} \frac{1}{\delta} \int_{0}^{\infty}\left[1+\delta L_{n}\left(t, T_{n}\right)\right] \\
& \left\{\exp \left[-\int_{t}^{T_{n+\delta}} h_{i}\left(t, x_{i}, u\right) d u\right]-\exp \left[-\int_{t}^{T_{n}} h_{i}\left(t, x_{i}, u\right) d u\right]\right\} \lambda_{i}^{Q} d t f(x) d x \\
& +\sum_{i=1}^{r} \frac{1}{\delta} \int_{0}^{\infty}\left[1+\delta L_{n}\left(t^{-}, T_{n}\right)\right]\left\{\exp \left[\int_{T_{n}}^{T_{n+\delta}} h_{i}\left(t, x_{i}, u\right) d u\right]-1\right\} d N_{i}(t) f(x) d x .
\end{aligned}
$$

From Brace, Gatarak and Musiela (1997), assuming that in each probability measure the stochastic process of LIBOR follows a lognormal distribution, the stochastic process of LIBOR becomes

$$
d L_{n}\left(t, T_{n}\right)=m_{n} L_{n}\left(t, T_{n}\right) d t+\gamma_{n} L_{n}\left(t, T_{n}\right) d W^{Q}(t)+L_{n}\left(t, T_{n}\right) d J_{n}(t),
$$


where $m_{n}$ is the drift rate, $\gamma_{n}$ is the diffusion rate, and $J_{n}(t)$ is the jump rate of LIBOR. Rearranging the diffusion rate component and comparing Eq. (12) with Eq. (13) we obtain

$$
\sigma^{*}\left(t, T_{n+1}\right)-\sigma^{*}\left(t, T_{n}\right)=\frac{\gamma_{n} \delta L_{n}\left(t, T_{n}\right)}{1+\delta L_{n}\left(t, T_{n}\right)}
$$

and

$$
\sigma^{*}\left(t, T_{n+1}\right)\left[\sigma^{*}\left(t, T_{n+1}\right)-\sigma^{*}\left(t, T_{n}\right)\right]=\frac{\gamma_{n} \delta L_{n}\left(t, T_{n}\right)}{1+\delta L_{n}\left(t, T_{n}\right)} \sigma^{*}\left(t, T_{n}\right)+\left[\frac{\gamma_{n} \delta L_{n}\left(t, T_{n}\right)}{1+\delta L_{n}\left(t, T_{n}\right)}\right]^{2}
$$

If the interval from $t$ to $u$ is smaller than $\delta$, i.e., $t<u<t+\delta, \sigma^{*}\left(t, T_{n}\right)=0$, then

$$
\gamma_{n} \delta L_{n}\left(t, T_{n}\right) \sigma^{*}\left(t, T_{n}\right)+\frac{\gamma_{n}^{2} \delta L_{n}^{2}\left(t, T_{n}\right)}{1+\delta L_{n}\left(t, T_{n}\right)}=\sum_{k=\eta_{(t)}}^{n} \frac{\gamma_{n} \gamma_{k} \delta L_{n}\left(t, T_{n}\right) L_{k}\left(t, T_{k}\right)}{1+\delta L_{n}\left(t, T_{n}\right)}
$$

Substituting Eq. (15) into Eq. (13), we obtain the LIBOR jump-diffusion process as

$$
\begin{aligned}
d L_{n}\left(t, T_{n}\right)= & {\left[\sum_{k=\eta_{(t)}}^{n} \frac{\gamma_{n} \gamma_{k} \delta L_{n}\left(t, T_{n}\right) L_{k}\left(t, T_{k}\right)}{1+\delta L_{n}\left(t, T_{n}\right)}\right] d t+\gamma_{n} L_{n}(t, T) d W^{Q}(t) } \\
& +\sum_{i=1}^{r} \frac{1}{\delta} \int_{0}^{\infty}\left[1+\delta L_{n}\left(t, T_{n}\right)\right] \\
& \left\{\exp \left[-\int_{t}^{T_{n+\delta}} h_{i}\left(t, x_{i}, u\right) d u\right]-\exp \left[-\int_{t}^{T_{n}} h_{i}\left(t, x_{i}, u\right) d u\right]\right\} \lambda_{i}^{Q} d t f(x) d x \\
& +\sum_{i=1}^{r} \frac{1}{\delta} \int_{0}^{\infty}\left[1+\delta L_{n}\left(t^{-}, T_{n}\right)\right]\left\{\exp \left[\int_{T_{n}}^{T_{n+\delta}} h_{i}\left(t, x_{i}, u\right) d u\right]-1\right\} d N_{i}(t) f(x) d x
\end{aligned}
$$

Rearranging the jump rate component, and let $H(Y)$ be the jump size function of LIBOR, then 


$$
\begin{aligned}
\frac{1}{\delta}\left[1+\delta L_{n}\left(t^{-}, T_{n}\right)\right]\left\{\exp \left[\int_{T_{n}}^{T_{n+\delta}} h_{i}\left(t, x_{i}, u\right) d u\right]-1\right\} & =L\left(t^{-}, T_{n}\right) H_{i}\left(x_{i}\right) \\
& =\frac{1}{\delta}\left\{\exp \left[\int_{T}^{T+\delta} f(t, u) d u\right]-1\right\} H_{i}\left(x_{i}\right) .
\end{aligned}
$$

After transposing we obtain

$$
H_{i}\left(x_{i}\right)=\frac{\left\{\exp \left[\int_{T}^{T+\delta} f(t, u) d u+\int_{T}^{T+\delta} h_{i}\left(t, x_{i}, u\right) d u\right]\right\}-1}{\left\{\exp \left[\int_{T}^{T+\delta} f(t, u) d u\right]-1\right\}}-1=Y_{i}-1
$$

where $Y_{i}$ stands for the jump ratio of LIBOR at the $i^{\text {th }}$ jump, and $Y_{i} \geq 1$,

$$
Y_{i}=\frac{\exp \left[\int_{T}^{T+\delta} f(t, u) d u+\int_{T}^{T+\delta} h\left(t, x_{i}, u\right) d u\right]-1}{\exp \left[\int_{T}^{T+\delta} f(t, u) d u\right]-1} .
$$

Influenced by the movement of the forward rate function $h\left(t, x_{i}, T\right)$, if jumps occur, $H\left(Y_{i}\right)=Y_{i}-1$; if not, $H\left(Y_{i}\right)=0$, and the jump rate compound Poisson process of LIBOR is

$$
\sum_{i=1}^{r} \int_{0}^{\infty} L_{n}\left(t-, T_{n}\right) H_{n i}\left(x_{i}\right) d N_{i}(t) d x f(x)=L\left(t^{-}, T_{n}\right) d \sum_{i=1}^{r} \sum_{n=1}^{N_{i}(t)} H_{n i}\left(x_{i}\right)
$$

and

$$
\exp \left[\int_{T_{n}}^{T_{n+\delta}} h(t, x, u) d u\right]=\frac{\delta L_{n}\left(t-, T_{n}\right) H_{n}\left(x_{i}\right)}{1+\delta L_{n}\left(t-, T_{n}\right)}+1=\frac{1+\delta L_{n}\left(t-, T_{n}\right)\left[1+H_{n}\left(x_{i}\right)\right]}{1+\delta L_{n}\left(t-, T_{n}\right)}
$$


Similar to the diffusion rate component, if $t<u<t+\delta, \exp \left[\int_{T_{n}}^{u} h\left(t, x_{i}, u\right) d u\right]=1$. Using this result to simplify the second term of Eq. (12), we obtain

$$
-\sum_{i=1}^{r} \int_{0}^{\infty} H_{n i}\left(x_{i}\right) L_{n}\left(t-, T_{n}\right) \prod_{k=\eta(t)}^{n} \frac{1+\delta L_{k}\left(t-, T_{k}\right)}{1+\delta L_{k}\left(t-, T_{k}\right)\left[1+H_{k i}\left(x_{i}\right)\right]} \lambda_{i}^{Q} d t f(x) d x
$$

Substituting Eq. (18) and Eq. (19) into Eq. (12) yields the stochastic process of LIBOR with risk-neutral probability as

$$
\begin{aligned}
d L_{n}\left(t, T_{n}\right)= & \left\{\sum_{k=\eta_{(t)}}^{n} \frac{\gamma_{n} \gamma_{k} \delta L_{n}\left(t, T_{n}\right) L_{k}\left(t, T_{k}\right)}{1+\delta L_{n}\left(t, T_{n}\right)}\right. \\
& \left.-\sum_{i=1}^{r} \int_{0}^{\infty} H_{n i}\left(x_{i}\right) L_{n}\left(t-, T_{n}\right) \prod_{k=\eta(t)}^{n} \frac{1+\delta L_{k}\left(t-, T_{k}\right)}{1+\delta L_{k}\left(t-, T_{k}\right)\left(1+H_{k i}\left(x_{i}\right)\right)} \lambda_{i}^{Q} d f(x) d x\right\} d t \\
& +\gamma_{n} L_{n}(t, T) d W^{Q}(t)+L\left(t-, T_{n}\right) d \sum_{i=1}^{r} \sum_{n=1}^{N_{i}(t)} H_{n i}\left(x_{i}\right) .
\end{aligned}
$$

\subsection{Forward measure of LIBOR market model}

Because the stochastic process of LIBOR involves many parameters under risk-neutral probability, it is difficult to price interest rate derivatives incorporating multi-period LIBOR. To simplify the model, we must transform the diffusion rate and jump rate parameters to the last pricing period. To do so, we rearrange the diffusion rate of Eq.(12) as

$$
d L_{n}\left(t, T_{n}\right)=\frac{1}{\delta}\left[1+\delta L_{n}\left(t, T_{n}\right)\right]\left[\sigma^{*}\left(t, T_{n+\delta}\right)-\sigma^{*}\left(t, T_{n}\right)\right]\left[\sigma^{*}\left(t, T_{n+\delta}\right) d t+d W^{Q}(t)\right]
$$

according to the theory of the transformation of probability measure

$$
\tilde{W}^{T+\delta}(t)=\int_{0}^{t} \sigma^{*}(u, T+u) d u+\tilde{W}(t)
$$


then Eq. (21) becomes

$$
d L_{n}\left(t, T_{n}\right)=\frac{1}{\delta}\left[1+\delta L_{n}\left(t, T_{n}\right)\right]\left[\sigma^{*}\left(t, T_{n+\delta}\right)-\sigma^{*}\left(t, T_{n}\right)\right] \tilde{W}^{T_{n+\delta}}(t) .
$$

Similar to Brace, Gatarak and Musiela (1997), let

$$
\begin{gathered}
d W^{T_{j}}(t)=\sigma^{*}\left(t, T_{j}\right) d t+d W^{Q}(t), \\
d W^{T_{j+1}}(t)=\sigma^{*}\left(t, T_{j+1}\right) d t+d W^{Q}(t) .
\end{gathered}
$$

Comparing these two functions, we obtain

$$
d W^{T_{j}}=\left[\sigma^{*}\left(t, T_{j}\right)-\sigma^{*}\left(t, T_{j+1}\right)\right] d t+d W^{T_{j+1}}(t)
$$

If we substitute the term $\left[\sigma^{*}\left(t, T_{j}\right)-\sigma^{*}\left(t, T_{j+1}\right)\right]$ from Eq. (14), then

$$
d W^{T_{j}}=-\frac{\gamma\left(t, T_{j}\right) \delta L\left(t, T_{j}\right)}{1+\delta L\left(t, T_{j}\right)} d t+d W^{T_{j}+1}(t)
$$

Letting $j=n$, we obtain

$$
d W^{T_{n}}=-\frac{\gamma\left(t, T_{n}\right) \delta L\left(t, T_{n}\right)}{1+\delta L\left(t, T_{n}\right)} d t+d W^{T_{n+1}}(t)
$$

Letting $j=n-1$, then

$$
\begin{aligned}
d W^{T_{n-1}} & =-\frac{\gamma\left(t, T_{n-1}\right) \delta L\left(t, T_{n-1}\right)}{1+\delta L\left(t, T_{n-1}\right)} d t+d W^{T_{n}}(t) \\
& =-\frac{\gamma\left(t, T_{n-1}\right) \delta L\left(t, T_{n-1}\right)}{1+\delta L\left(t, T_{n-1}\right)} d t-\frac{\gamma\left(t, T_{n}\right) \delta L\left(t, T_{n}\right)}{1+\delta L\left(t, T_{n}\right)}+d W^{T_{n+1}}(t)
\end{aligned}
$$


Repeating this process, we have

$$
d W^{T_{j+1}}=-\sum_{i=j+1}^{n} \frac{\gamma\left(t, T_{i}\right) \delta L\left(t, T_{i}\right)}{1+\delta L\left(t, T_{i}\right)} d t+d W^{T_{n+1}}(t)
$$

Substituting Eq. (23) into Eq. (12), and unifying the multiple-period Brownian motion measures, we obtain

$$
\begin{aligned}
d L_{n}\left(t, T_{n}\right)= & \frac{1}{\delta}\left[1+\delta L_{n}\left(t, T_{n}\right)\right]\left[\sigma^{*}\left(t, T_{n+\delta}\right)-\sigma^{*}\left(t, T_{n}\right)\right]\left[-\sum_{i=n+1}^{M} \frac{\gamma\left(t, T_{i}\right) \delta L\left(t, T_{i}\right)}{1+\delta L\left(t, T_{i}\right)} d t\right] \\
& +\frac{1}{\delta}\left[1+\delta L_{n}(t, T)\right]\left[\sigma^{*}\left(t, T_{n+1}\right)-\sigma^{*}\left(t, T_{M+1}\right)\right] d W_{M+1}(t) .
\end{aligned}
$$

According to Björk, Kabanov and Runggaldier (1997) the condition for transforming $\lambda^{Q}$ to the last pricing period is

$$
\lambda_{T+\delta}=e^{-\int_{t}^{T+\delta} h(t, x, u) d u} \lambda^{Q}
$$

In Eq. (16) the transformation process of $\lambda^{Q}$ measure is

$$
\begin{aligned}
& \frac{1}{\delta}\left[1+\delta L_{n}\left(t, T_{n}\right)\right] e^{\int_{T_{n}}^{T_{M+1}} h\left(t, x_{i}, u\right) d u}\left[e^{-\int_{T_{n}}^{T_{n+1}} h\left(t, x_{i}, u\right) d u}-1\right] \lambda_{M+1} d t \\
& =\frac{1}{\delta}\left[1+\delta L_{n}\left(t, T_{n}\right)\right] e^{\int_{T_{n+1}}^{T_{M+1}} h\left(t, x_{i}, u\right) d u}\left[1-e^{\int_{T_{n}}^{T_{n+1}} h\left(t, x_{i}, u\right) d u}\right] \lambda_{M+1} d t \\
& =-H\left(Y_{i}\right) L_{n}\left(t-, T_{n}\right) e^{\int_{T_{n+1}}^{T_{M+1}} h\left(t, x_{i}, u\right) d u} \lambda_{M+1} d t \\
& =-H\left(Y_{i}\right) L_{n}\left(t-, T_{n}\right) \prod_{k=n+1}^{M} \frac{1+\delta L_{k}\left(t-, T_{k}\right)\left(1+H\left(t_{k}\right)\right)}{1+\delta L_{k}\left(t-, T_{k}\right)} \lambda_{M+1} d t .
\end{aligned}
$$

Letting $n=M$ and substituting Eq. (25) into Eq. (13), we obtain the LIBOR market model of forward rate measurement with jump risk as 


$$
d L_{n}(t, T)=\alpha_{n} L_{n}(t, T) d t+\gamma_{n} L_{n}(t, T) d W_{M+1}(t)+L_{n}(t, T) d J_{n}(t)
$$

where

$$
\begin{gathered}
\alpha_{n}=-\sum_{k=n+1}^{n} \frac{\gamma_{i}\left(t, T_{i}\right) \gamma_{k}\left(t, T_{k}\right) \delta L\left(t, T_{i}\right)}{1+\delta L\left(t, T_{i}\right)} \\
-\int_{0}^{\infty} \sum_{i=1}^{r} H_{n}(t) L_{n}\left(t-, T_{n}\right) \prod_{k=n+1}^{M} \frac{1+\delta L_{k}\left(t-, T_{k}\right)\left[1+H_{k}(t)\right]}{1+\delta L_{k}\left(t-, T_{k}\right)} \lambda_{M+1} f(x) d x, \\
d J_{n}(t)=d \sum_{i=1}^{r} \sum_{n=1}^{N_{i}(t)} H_{n i}\left(x_{i}\right) f(x) .
\end{gathered}
$$

If $n=M$, then

$$
\begin{gathered}
{\left[\sigma^{*}\left(t, T_{n+1}\right)-\sigma^{*}\left(t, T_{M+1}\right)\right]=0} \\
-H_{n i}\left(x_{i}\right) L_{n}\left(t^{-}, T_{n}\right) e^{\int_{T_{n+1}}^{T_{M+1}} h_{i}\left(t, x_{i}, u\right) d u} \lambda_{M+1} d t=-H_{n i}\left(x_{i}\right) L_{n} .
\end{gathered}
$$

Eq. (26) can be simplified as

$$
d L_{M}(t, T) / L_{M}\left(t-, T_{M}\right)=\gamma_{M}(t) d W^{M+1}(t)+d J_{M}(t)-\int_{0}^{\infty} \sum_{i=1}^{r} H_{M i}\left(x_{i}\right) \lambda_{M+1}^{i} d t f(x) d x .
$$

\subsection{The pricing model of Range Accrual Interest Rate Swap}

The value of cash inflows for floating-rate payer at the maturity of RAIRS is

$$
\operatorname{RNIRS}\left(t, T_{i}, T_{i+1}\right)=\left(\sum_{q=1}^{4} \frac{a^{*} N_{q}}{D}-\sum_{q=1}^{4} \frac{K}{4}\right) \times F,
$$

where $N_{q}$ is the number of calendar days between swaps, and $K$ is the fixed rate paid by the fixed-rate payer. Assuming 30 trading days per month and 3 months per period, the number of trading days will be 90 per period. The pricing model of floating-rate payer in risk neutral 
probability is thus

$$
\begin{aligned}
\operatorname{RNIRS}\left(t, T_{q}, T_{q+1}\right) & =\sum_{q=1}^{4} \sum_{l=1}^{90} B\left(t, T_{q}+l\right) X\left\{E^{Q}\left[1_{\left\{K_{2}>L\left(T_{q}+l, T_{q+1}+l\right)>K_{1}\right\}}\right]\right\} \times \frac{B\left(t, T_{q}\right)}{B\left(t, T_{q}+l\right)} \times F \\
& -\sum_{q=1}^{4} B\left(t, T_{q}\right) \frac{K}{4} \times F
\end{aligned}
$$

where $q$ is the number of swaps in the trading period; $l$ is the number of days between swaps; $B\left(t, T_{q}\right) / B\left(t, T_{q}+l\right)$ stands for the discount factor of Range Accrual Bond in a Martingale process; $B\left(t, T_{q}+l\right)$ is the value of the zero-coupon bond at termination; $X$ is the agreed swap rate, $X=a / D$ measured in years from today. Eq. (28) can be decomposed as

$$
\begin{aligned}
R N I R S\left(t, T_{q}, T_{q+1}\right)= & \sum_{q=1}^{4} \sum_{l=1}^{90} B\left(t, T_{q}+l\right)\left\{E^{Q} X\left[1_{\left\{K_{2}>L\left(T_{q}, T_{q+1}+l\right)>K_{1}\right\}}\right]\right\} F \cdot \frac{B\left(t, T_{q}\right)}{B\left(t, T_{q}+l\right)} \\
& -\sum_{q=1}^{4} B\left(t, T_{q}\right) \frac{K}{4} F \\
= & F\left\{\sum_{q=1}^{4} \sum_{l=1}^{90} B\left(t, T_{q}+l\right) X \sum_{j=0}^{\infty} \frac{e^{-\lambda_{l}(T+l-t)} \lambda_{l}(T+l-t)^{j}}{j !}\left[N\left(d_{1, i j}\right)-N\left(d_{2, i j}\right)\right]\right. \\
& \left.\frac{B\left(t, T_{q}\right)}{B\left(t, T_{q}+l\right)}-\sum_{q=1}^{4} B\left(t, T_{q}\right) \frac{K}{4}\right\} \\
= & F \times[\tilde{A}-\tilde{B}],
\end{aligned}
$$

where $F \times \tilde{A}$ is the floating rate interest received by the fixed rate payer. On the other hand, $F \times \tilde{B}$ is the fixed rate interest received by the floating rate payer.

$$
\begin{gathered}
d_{1, i j}=\frac{\ln \frac{L\left(t, T_{q}+l\right)^{(i j)}}{K_{1}}-\frac{1}{2} \sigma_{i j}^{2}\left(T_{q}+l-t\right)}{\sqrt{\sigma_{i j}^{2}\left(T_{q}+l-t\right)}}, d_{2, i j}=\frac{\ln \frac{L\left(t, T_{q}+l\right)^{(i j)}}{K_{2}}-\frac{1}{2} \sigma_{i j}^{2}\left(T_{q}+l-t\right)}{\sqrt{\sigma_{i j}^{2}\left(T_{q}+l-t\right)}}, \\
L\left(t, T_{q}+l\right)^{(i j)}=L\left(t, T_{q}+l\right) \exp \left[\sum_{i=1}^{r}-\lambda_{l i} m_{l i}\left(T_{q}+l-t\right)\right] \prod_{i=1}^{r}\left(1+m_{l i}\right)^{j_{i}} .
\end{gathered}
$$


Let the price of RAIRS be equal to zero, then the fixed interest rate $K$ (swap rate) is

$$
K=\frac{4}{\sum_{q=1}^{4} B\left(t, T_{q}\right)} \sum_{q=1}^{4} \sum_{l=1}^{90} B\left(t, T_{q}+l\right) X \sum_{j=0}^{\infty} \frac{e^{-\lambda_{l}(T+l-t)} \lambda_{l}(T+l-t)^{j}}{j !}\left[N\left(d_{1, j}\right)-N\left(d_{2, j}\right)\right] \frac{B\left(t, T_{q}\right)}{B\left(t, T_{q}+l\right)} .
$$

\section{Numerical Analysis}

In this section, we use a numerical analysis to demonstrate the relationship between swap rate and jump size, jump frequency, and jump volatility of a RAIRS. Assume a value for RAIRS equal to zero, a duration of contract of one year, 360 days in a year, and payments swapped every 3 months - four swaps per year. The interest rate floor is $0 \%$ and the cap is $2.5 \%, 3$-month USD LIBOR is $1.8 \%$ at time $t=0$, the volatility of 3 -month USD LIBOR is 0.05. Two independent jump processes are assumed in the pricing period. The first one is induced by stronger information, which has a dramatic influence on the jump process of LIBOR. On the contrary, the second is associated with weaker information. The corresponding jump sizes are $0.01\left(m_{1}=0.01\right)$ and $0.5\left(m_{2}=0.5\right)$; the corresponding jump volatilities are $0.15\left(s_{1}=0.15\right)$ and $0.45\left(s_{2}=0.45\right)$; and the corresponding jump frequencies are 0.5 $\left(\lambda_{1}=0.5\right)$ and $1.5\left(\lambda_{2}=1.5\right)$, respectively. The value of the zero coupon bond declines $\$ 0.0001$ mark-to-market starting at $\$ 0.90$.

\subsection{The impact of jump size on the swap rate of RAIRS}

From Table 2, when jump sizes $m_{1}$ and $m_{2}$ change (within an interval from 0 to 0.6), the swap rate of RAIRS will decrease with the increase of the expected value of jump size, and the smaller the initial swap rate, the less valuable the RAIRS will be. When evaluating the LIBOR in risk-neutral probability, potential jump size due to information emergence must be eliminated in the initial pricing to ensure an arbitrage-free condition. Therefore, when jump 
size gradually increases due to information emergence, the initial value for LIBOR will become smaller, as does the value of underlying assets. Since this is disadvantageous to the floater, the value of RAIRS will be smaller.

In addition, from Table 2, Figure 3, and Figure 4, $m_{2}$ has greater impact on the swap rate of the RAIRS than $m_{1}$, because jump size $m_{2}>m_{1}$.

Table 2. Jump size changes and the swap rate of the RAIRS

\begin{tabular}{cccc}
\hline $\begin{array}{c}\text { Changes in } \\
\text { jump size } m_{1}\end{array}$ & $\begin{array}{c}\text { The swap rate of RAIRS } \\
\text { corresponding to } m_{1}\end{array}$ & $\begin{array}{c}\text { Changes in } \\
\text { jump size } m_{2}\end{array}$ & $\begin{array}{c}\text { The swap rate of RAIRS } \\
\text { corresponding to } m_{2}\end{array}$ \\
\hline 0.0 & 0.0237 & 0.0 & 0.0237 \\
0.1 & 0.0228 & 0.1 & 0.0221 \\
0.2 & 0.0220 & 0.2 & 0.0207 \\
0.3 & 0.0213 & 0.3 & 0.0195 \\
0.4 & 0.0206 & 0.4 & 0.0184 \\
0.5 & 0.0201 & 0.5 & 0.0174 \\
0.6 & 0.0195 & 0.6 & 0.0166 \\
\hline
\end{tabular}

Note: Initial jump sizes are $m_{1}=0.01$ and $m_{2}=0.5$. 


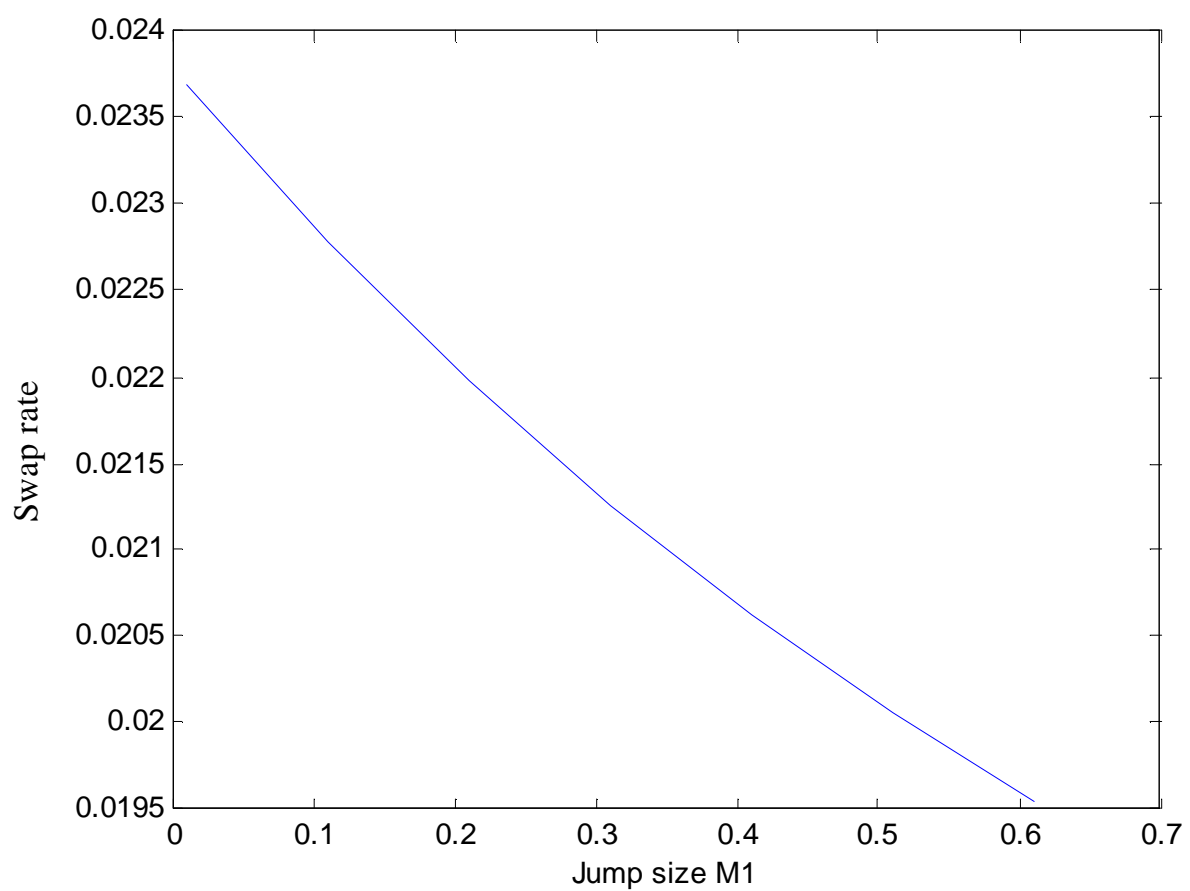

Figure 3. The relationship between jump size $m_{1}$ and the swap rate of the RAIRS

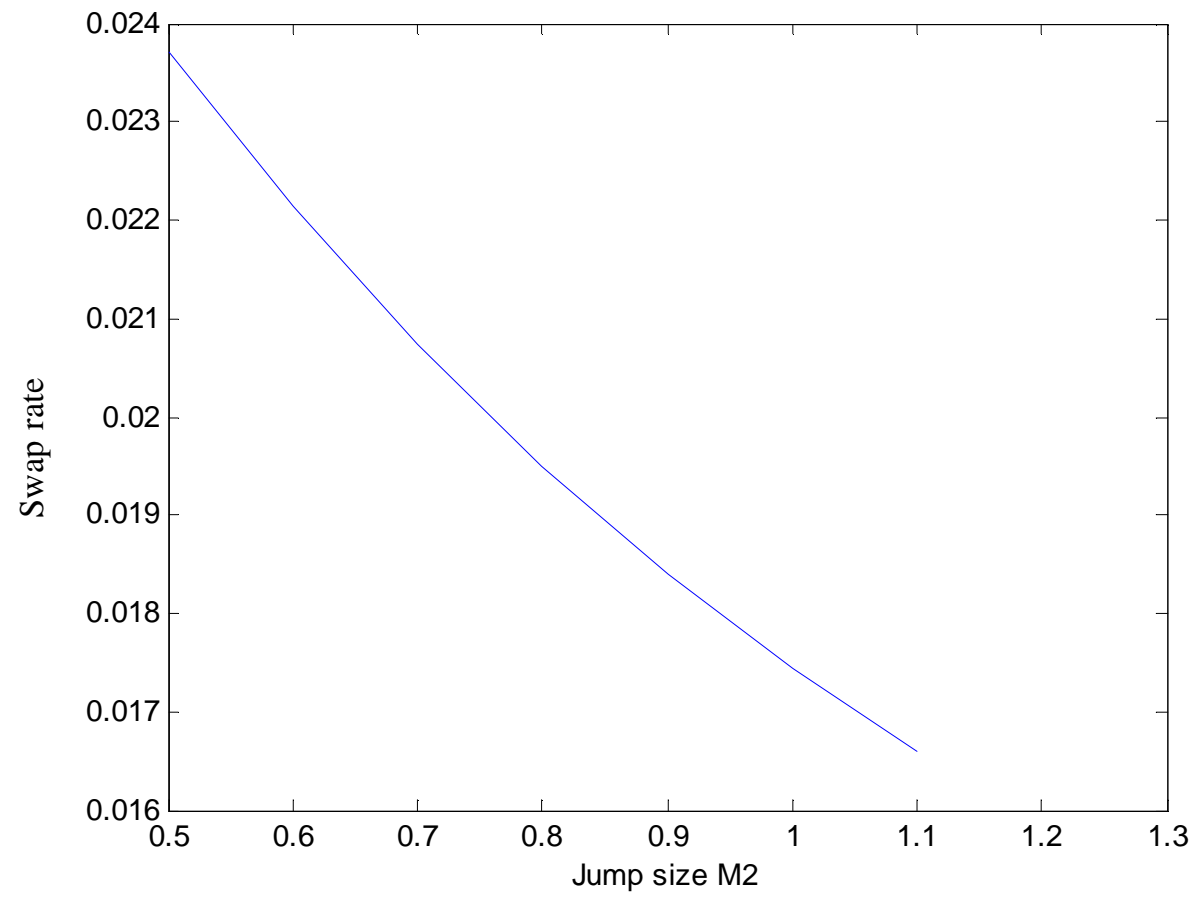

Figure 4. The relationship between jump size $m_{2}$ and the swap rate of the RAIRS 


\subsection{The impact of jump volatility on the swap rate of RAIRS}

From Table 3, when jump volatilities $s_{1}$ and $s_{2}$ increase (within an interval from 0 to 0.3), the swap rate of RAIRS also increases. This is because when jump volatility increases, the total volatility of RAIRS follows suit. Hence when jump volatility increases, both parties of the RAIRS must accept a higher swap rate because the floating rate payer is subsidized by the fixed rate payer for bearing risk. The higher the swap rate is, the higher the value of RAIRS will be.

Similarly, from Table 3, Figure 5, and Figure 6, $s_{2}$ has greater impact on the swap rate of RAIRS relative to $s_{1}$, because $s_{2}>s_{1}$. This result is consistent with our assumption described earlier in this section.

Table 3. Jump volatility changes and the swap rate of RAIRS

\begin{tabular}{cccc}
\hline $\begin{array}{c}\text { Changes in jump } \\
\text { volatility } s_{1}\end{array}$ & $\begin{array}{c}\text { The swap rate of } \\
\text { RAIRS corresponding } \\
\text { to } s_{1}\end{array}$ & $\begin{array}{c}\text { Changes in jump } \\
\text { volatility } s_{2}\end{array}$ & $\begin{array}{c}\text { The swap rate of RAIRS } \\
\text { corresponding to } s_{2}\end{array}$ \\
\hline 0.00 & 0.0237 & 0.00 & 0.0237 \\
0.05 & 0.0240 & 0.05 & 0.0245 \\
0.10 & 0.0242 & 0.10 & 0.0252 \\
0.15 & 0.0245 & 0.15 & 0.0259 \\
0.20 & 0.0247 & 0.20 & 0.0265 \\
0.25 & 0.0250 & 0.25 & 0.0271 \\
0.30 & 0.0252 & 0.30 & 0.0276 \\
\hline
\end{tabular}

Note: Initial jump volatilities are $s_{1}=0.15$, and $s_{2}=0.45$. 


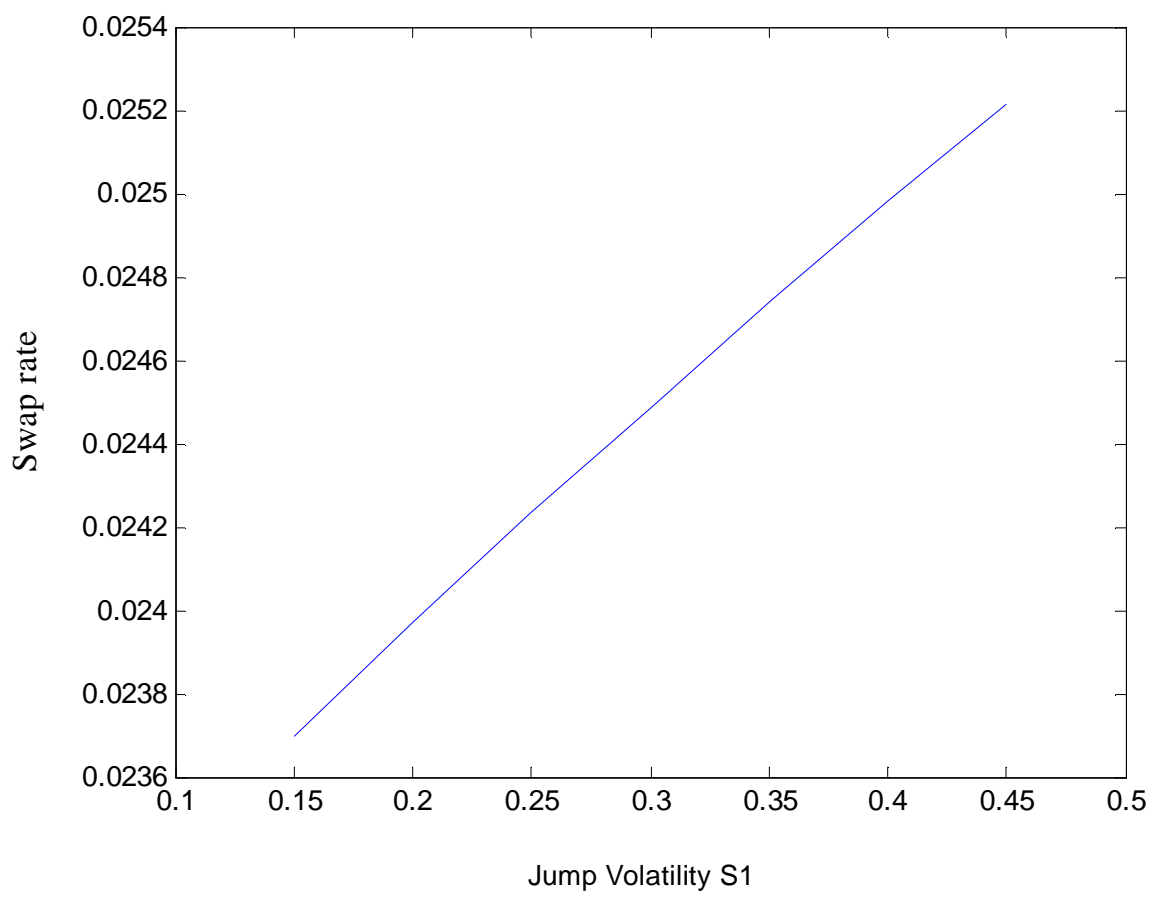

Figure 5. The relationship between jump volatility $s_{1}$ and the swap rate of RAIRS

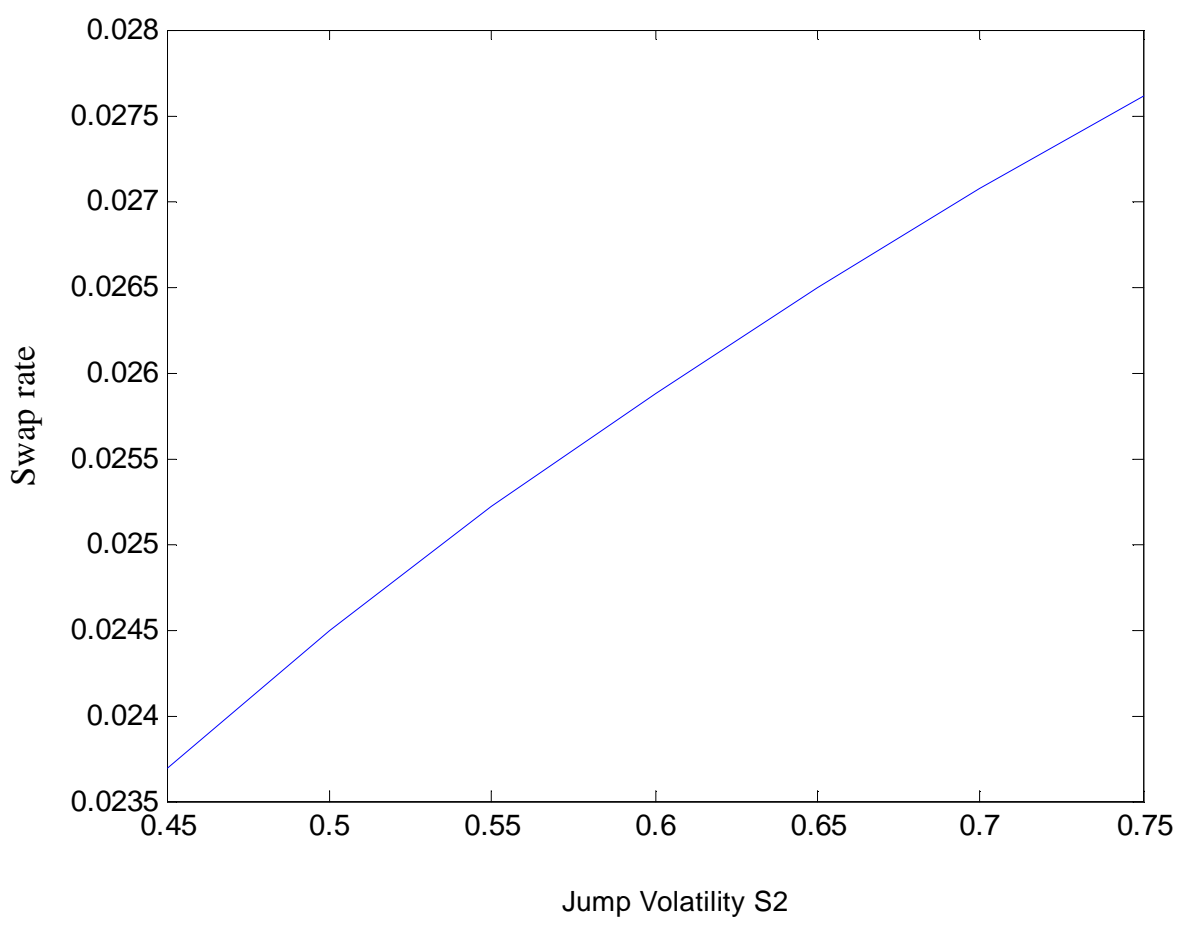

Figure 6. The relationship between jump volatility $s_{2}$ and the swap rate of RAIRS

\subsection{The impact of jump frequency on the swap rate of RAIRS}


From Table 4, when jump frequency $\left(\lambda_{1}\right.$ and $\left.\lambda_{2}\right)$ increases (within an interval from 0 to 0.45), the swap rate of RAIRS decreases. This result can be obtained from Eq. (29)—there exists a negative relation between jump frequency $\lambda_{1}$ and the swap rate of RAIRS. From probability theory, we know that given the frequency of actual occurrence, the value of the probability decreases when the expected value of the Poisson distribution increases, which is consistent with our RAIRS pricing model. From an investor's viewpoint, the higher jump frequency of LIBOR is associated with higher uncertainty risk, hence a decline in the value of RAIRS can be regarded as the additional market premium for bearing risk.

Similarly, from Table 4, Figure 7 and Figure $8, \lambda_{2}$ has greater impact on the swap rate of RAIRS relative to $\lambda_{1}$ because jump frequency $\lambda_{2}>\lambda_{1}$.

Table 4. Jump frequency changes and the swap rate of RAIRS

\begin{tabular}{cccc}
\hline $\begin{array}{c}\text { Changes in jump } \\
\text { frequency } \lambda_{1}\end{array}$ & $\begin{array}{c}\text { The swap rate of RAIRS } \\
\text { corresponds to } \lambda_{1}\end{array}$ & $\begin{array}{c}\text { Changes in jump } \\
\text { frequency } \lambda_{2}\end{array}$ & $\begin{array}{c}\text { The swap rate of RAIRS } \\
\text { corresponds to } \lambda_{2}\end{array}$ \\
\hline 0.0 & 0.0237 & 0.0 & 0.0237 \\
0.1 & 0.0235 & 0.1 & 0.0216 \\
0.2 & 0.0234 & 0.2 & 0.0195 \\
0.3 & 0.0232 & 0.3 & 0.0178 \\
0.4 & 0.0230 & 0.4 & 0.0159 \\
0.5 & 0.0228 & 0.5 & 0.0136 \\
0.6 & 0.0226 & 0.6 & 0.0119 \\
\hline
\end{tabular}

Note: Initial jump frequencies are $\lambda_{1}=0.5$ and $\lambda_{2}=1.5$. 


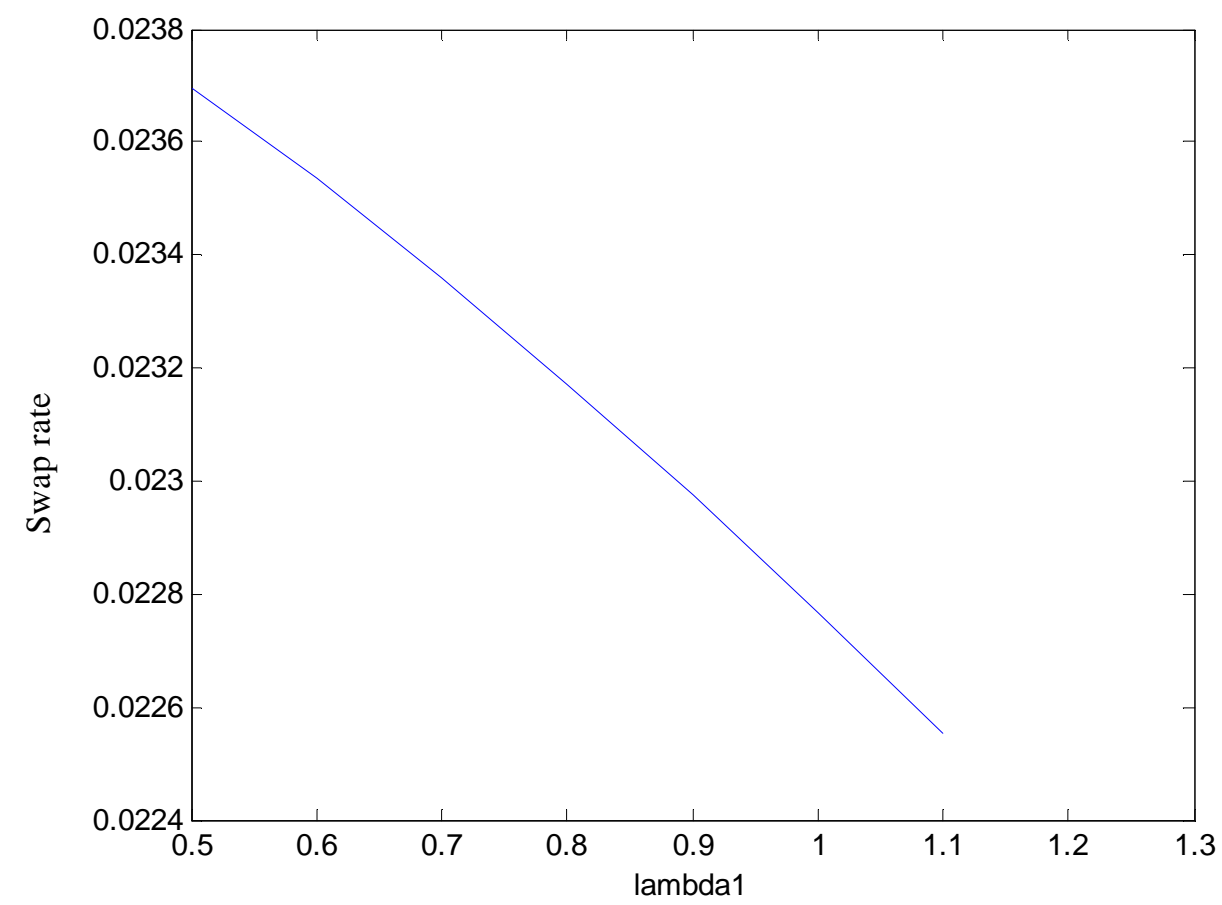

Figure 7. The relationship between jump frequency $\lambda_{1}$ and the swap rate of RAIRS

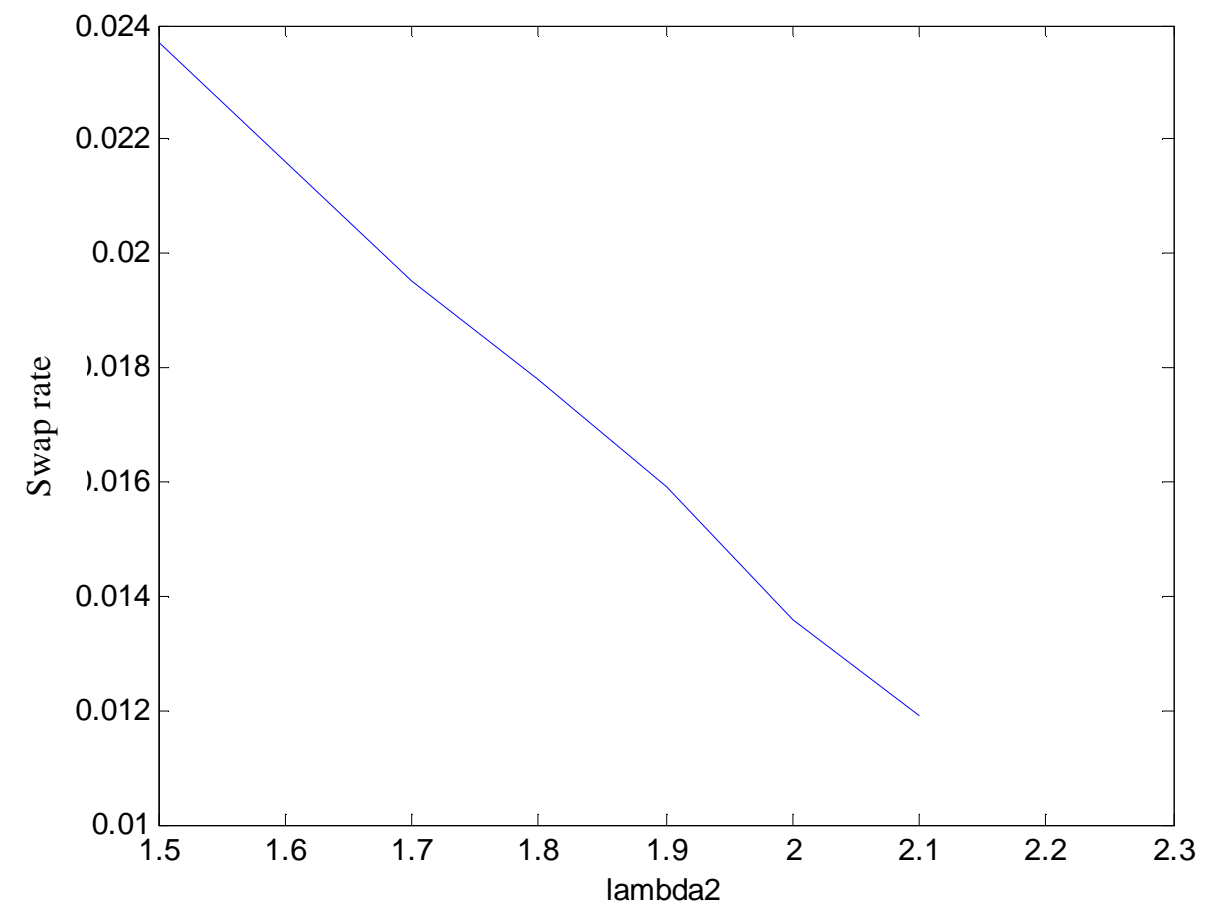

Figure 8. The relationship between jump frequency $\lambda_{2}$ and the swap rate of RAIRS 


\section{Conclusions}

Interest rates constitute an important economic index. Since the jump process of interest rates is discontinuous in the event of sudden information emergence, we derive the LIBOR market model with jump risk. Since interest rates often follow multiple independent jump processes, it would be more accurate to use our model to price the derivatives. To this end, we use numerical analysis to illustrate the influence of jump size, jump volatility, and jump frequency on the pricing of RAIRS.

Numerical analysis shows that there is a negative relation between jump size, jump frequency, and the swap rate of RAIRS. However, there is a positive relation between jump volatility and the swap rate of RAIRS, meaning the larger the jump volatility, the higher the value of RAIRS. Furthermore, the stronger the LIBOR-related information, the greater will be the impact of jump risk on RAIRS. From the numerical results, we know that increases in jump size will decrease the value of LIBOR in time $t=0$. Since this is disadvantageous to the floater, the value of RAIRS will decrease. Similarly, the higher the jump frequency of LIBOR, the greater the uncertainty risk, hence the value of RAIRS declines because investors are paid with a premium to bear risk. On the other hand, when jump volatility increases, both parties must agree to a higher swap rate because the floating rate payer is subsidized by the fixed rate payer for bearing risk. 


\section{References}

Black, F., and M. Scholes, 1973, The pricing of options and corporate liabilities, Journal of Political Economy, 81(3), 637-654.

Björk, T., Y. Kabanov and W. Runggaldier, 1997, Bond Market Structure in the Presence of Market Point Process, Mathematical Finance, 7, 211-239.

Brace, A., D. Gatarak and M. Musiela, 1997, The Market Model of Interest Rate Dynamics, Mathematical Finance, 7, 127-155.

Chiarella, C. and T. D. To, 2003, The Jump Component of The Volatility Structure of Interest Rate Futures Markets, The Journal of Futures Markets, 23(12), 1125-1158.

Cox, J. C., J. E. Ingersoll and S. A. Ross, 1985, A Theory of the Term Structure of Interest Rates, Econometrica, 53, 385-407.

Elliott, R. J., 1982, Stochastic Calculus and Application, New York: Springer-Verlag.

Heath, D., R. Jarrow and A. Morton, 1992, Bond Price and the Term Structure of Interest Rates: A New Methodology for Contingent Claims Valuation, Econometrica, 60, 77-105.

Ho, T. S. Y. and S. B. Lee, 1986, Term Structure Movements and the Pricing of Interest Rate Contingent Claims, The Journal of Finance, 41, 1011-1029.

Hull, J. and A. White, 1990, Pricing Interest Rate Derivative Securities, The Review of Financial Studies, 3, 573-592.

Merton, R., 1976, Option Pricing when Underlying Stock Returns are Discontinuous, Journal of Financial Economics, 3, 125-144.

Shikarawa, H., 1991, Interest Rate Option Pricing with Poisson-Gaussian Forward Rate Curve Process, Mathematical Finance, 1, 77-94.

Vasicek, O., 1977, An Equilibrium Characterization of the Term Structure, Journal of Financial Economics, 5, 177-188. 